\title{
Cost-utility analysis of an intervention designed to reduce the critical handling error of insufficient inspiratory effort
}

\author{
Rebecca Forster $^{1} \cdot$ Aran Ratcliffe $^{2} \cdot$ Megan Lewis $^{2} \cdot$ Amy Crossley $^{2} \cdot J_{\text {Julio López Bastida }}{ }^{3} \cdot$ William C. N. Dunlop $^{1}$
}

Received: 3 November 2017 / Accepted: 3 April 2018 / Published online: 12 May 2018

(c) The Author(s) 2018

\begin{abstract}
Objectives Up to 70-80\% of patients use inhalers incorrectly. Dry-powder inhalers (DPIs) require forceful inhalation for optimal delivery, and approximately 40\% of Global Initiative for Asthma (GINA)-defined Step-3+ patients inhale corticosteroid and long-acting beta-agonist through DPIs. The CRITIKAL study (Price et al. in J Allergy Clin Immunol Pract 5:1071-e9-1081-e9, 2017) found a statistically significant association between 'insufficient inspiratory effort' error and increased risk of uncontrolled asthma and hospitalisation-requiring exacerbations. This paper explores the cost-effectiveness of an error-targeted intervention. Methods A probabilistic Markov cost-utility model simulated patients transitioning between controlled and uncontrolled health states over one year. Odds ratios (ORs, from the CRITIKAL study) of a patient having uncontrolled asthma conditional on making the error were applied to baseline transition probabilities sourced from the literature, both indirectly via an adjustment formula (Zhang et al. in JAMA 280:1690-1691, 1998) and directly by assuming OR approximates relative risk (RR). The analysis explored complete/partial eradication of the error when the intervention was priced to match comparators, as well as impact of indirect costs based on lost/reduced productivity.

Results The intervention dominated both DPI comparators over one year, with direct cost savings of $£ 45 / £ 86$ with 0.0053/0.0102 additional quality-adjusted life years (QALYs), and had the highest probability of being cost-effective at a $£ 20,000 / Q A L Y$ threshold. Key factors driving variance were weekly utilities per state and RR of moving to an uncontrolled state.

Conclusion The analysis demonstrated the economic and societal costs of 'insufficient inspiratory effort' and potential economic benefits of introducing an effective intervention to reduce/eradicate this error. Further research should assess the economic impact of other handling errors.
\end{abstract}

Keywords Critical handling error $\cdot$ Cost-utility analysis $\cdot$ Asthma inhaler device $\cdot$ Dry-powder inhaler

\section{JEL Classification I1}

Electronic supplementary material The online version of this article (https://doi.org/10.1007/s10198-018-0974-2) contains supplementary material, which is available to authorized users.

William C. N. Dunlop

Will.Dunlop@mundipharma.com

Rebecca Forster

Rebecca.Forster@mundipharma.com

Aran Ratcliffe

Aran.Ratcliffe@ adelphivalues.com

Megan Lewis

Megan.Lewis@adelphivalues.com

Amy Crossley

Amy.Crossley@adelphivalues.com

\section{Abbreviations}

$\begin{array}{ll}\text { BMI } & \text { Body Mass Index } \\ \text { BNF } & \text { British National Formulary } \\ \text { CEAC } & \text { Cost-effectiveness acceptability curve }\end{array}$

Julio López Bastida

Julio.Lopezbastida@uclm.es

1 Mundipharma International Ltd, Cambridge Science Park, Cambridge CB4 0AB, UK

2 Adelphi Values Ltd, Adelphi Mill, Macclesfield, Cheshire SK10 5JB, UK

3 Universidad Castilla-La Mancha, Talavera de la Reina, Toledo, Spain 


$\begin{array}{ll}\text { CI } & \text { Confidence interval } \\ \text { DPI } & \text { Dry-powder inhaler } \\ \text { DSA } & \text { Deterministic sensitivity analysis } \\ \text { GINA } & \text { Global Initiative for Asthma } \\ \text { ICER } & \text { Incremental cost-effectiveness ratio } \\ \text { ICS } & \text { Inhaled corticosteroids } \\ \text { INMB } & \text { Incremental net monetary benefit } \\ \text { LABA } & \text { Long-acting beta-agonists } \\ \text { MAICER } & \text { Maximum acceptability incremental cost- } \\ & \text { effectiveness ratio } \\ \text { MDI } & \text { Metered-dose inhaler } \\ \text { NHS } & \text { National Health Service } \\ \text { NICE } & \text { National Institute for Health and Care } \\ & \text { Excellence } \\ \text { NMB } & \text { Net monetary benefit } \\ \text { ONS } & \text { Office for National Statistics } \\ \text { OR } & \text { Odds ratio } \\ \text { PSA } & \text { Probabilistic sensitivity analysis } \\ \text { PSSRU } & \text { Personal Social Services Research Unit } \\ \text { QALY } & \text { Quality-adjusted life year } \\ \text { RR } & \text { Relative risk } \\ \text { SE } & \text { Standard error } \\ \text { WTP } & \text { Willingness to pay }\end{array}$

\section{Introduction}

Asthma affects over 200 million people globally [1], and uncontrolled asthma is associated with poor quality of life, activity impairment, and increased resource use [2-4].

The GINA has published treatment recommendations for patients with poor asthma control. Inhaled corticosteroid (ICS) combined with a long-acting beta-agonist (LABA) therapy is recommended in cases where low-dose ICS is insufficient as controller medication (classed as GINA Step 3 and above) [5]. In the UK, several device options currently exist including metered-dose inhalers (MDIs) and DPIs, with DPIs taking a significant market share (approximately 40\%) for ICS/LABA combinations [6].

According to GINA 2017 guidelines, up to $70-80 \%$ of patients with asthma use their inhaler incorrectly [5], which could lead to a reduction in the amount of drug delivered and could therefore impact effectiveness in terms of symptom control. This is especially true for 'critical' handling errors, which have previously been defined in the literature as those "likely to significantly impair delivery of adequate medication" [7]. A systematic literature review assessed the potential burden of critical handling errors for asthmatic patients. Within that review, one study estimated that patients with asthma making at least one critical handling error resulted in an additional 19 hospitalisations and 26.5 emergency room visits per 100 patients in Italy [8].
The CRITIKAL study was the first, to the authors' knowledge, to analyse the association between specific inhaler handling errors and asthma control [9]. This study examined iHARP asthma review data of 3660 patients aged 16 years or older using different inhaler types, including DPIs, for the administration of ICS/LABA treatment, and looked at the frequency of critical handling errors and their association with asthma outcomes such as asthma control and exacerbation rates.

For patients using a DPI inhaler (2900 patients), the critical handling error of 'insufficient inspiratory effort' occurred in $32 \%$ and $38 \%$ of patients using either a Turbohaler ${ }^{\circledR}$ DPI or a Diskus ${ }^{\circledR}$ DPI, respectively. This was the only critical handling error that was statistically significantly associated with both poor asthma control (after adjusting for other patient factors including age, smoking status and adherence) and an increased risk of exacerbations [9].

For the relationship between this critical handling error and poor asthma control, the adjusted OR was 1.30 (95\% confidence interval (CI) $[1.08,1.57]$ for Turbohaler $\left.{ }^{\circledR} \mathrm{DPI}\right)$ and 1.56 (95\% CI [1.17, 2.07] for Diskus ${ }^{\circledR}$ DPI). These ORs [9] were adjusted by all errors, and patient factors including age, sex, smoking status and body mass index (BMI), and adherence score. The 'insufficient inspiratory effort' critical handling error was the only one that remained statistically significant after these adjustments. The lack of ability to inhale deeply and forcefully is a common error in some patient groups, such as very elderly patients, and may be challenging to overcome even with additional training [10].

Given the significant association demonstrated by the CRITIKAL study between the specific critical handling error of 'insufficient inspiratory force' and asthma control, there is an unmet need for an effective intervention, such as either more effective training or an inhaler that reduces the incidence of this critical handling error, and therefore potentially provides increased asthma control, health-related quality-of-life and a reduction in overall resource use.

The objective of this study was to evaluate the economic and societal impact of eradicating the critical handling error of 'insufficient inspiratory effort', through the assumed adoption of an effective intervention (hereafter referred to as an errortargeted intervention) which eradicates or reduces this error.

A previous structured literature search identified a budget impact model in the UK for patients with asthma and chronic obstructive pulmonary disease. They estimated the resource use and costs in patients who had an increased risk of serious exacerbations due to uncontrolled asthma [7]. However, this did not specify a link between critical handling errors arising from the use of an inhaler with either uncontrolled asthma or an increased risk of exacerbations. Therefore, to the authors' knowledge, this is the first economic model to examine the societal and economic costs of a single critical handling error. 


\section{Methodology}

\section{Decision problem and rationale}

A previous structured literature review of economic models in asthma identified 31 published cost-effectiveness models for asthma [11]. Many of the features of the models identified in the literature were utilised; including a Markov model structure and utility values from the Briggs et al. [12] model. However, full use of the existing models was limited as they did not include results specific to handling errors with asthma inhalers.

A new cost-utility model was therefore developed using Microsoft ${ }^{\circledR}$ Excel 2010 and R-3.4.1, to estimate the economic and social impact of the critical handling error of 'insufficient inspiratory effort'. The cost-utility model included patients defined as GINA Step 3 and above receiving ICS/ LABA therapy via one of two DPIs, Diskus ${ }^{\circledR}$ or Turbohaler ${ }^{\circledR}$, or an error-targeted intervention. These were the only DPIs assessed in the CRITIKAL study and were therefore deemed suitable for inclusion within this analysis [9].

The analysis takes the perspective of the National Health Service (NHS), the wider economy, and patients in the UK; therefore, the model included both direct (device costs and resource use) and indirect (productivity loss/reduction) costs as well as patients' health-related quality-of-life in the form of utility values.

\section{Patient population}

The patient population within this analysis matches that of the CRITIKAL study. The population of interest for this model is patients aged 16 years or over receiving Step 3 and above GINA-defined asthma therapy (ICS/LABA) in the UK, administered by DPIs. As this included patients of both sexes, as well as a range of BMIs, smoking status, age and other patient factors, the CRITIKAL study adjusted ORs based on these factors. Sub-group analyses were not feasible due to the absence of the reporting of the 'non-handling error' coefficients.

\section{Model structure}

A two state Markov model was developed where patients could either be in a controlled asthma state or an uncontrolled asthma state (see Fig. 1). The decision to build a two state model was made to ensure consistency with the CRITIKAL study which reported the OR of moving to a

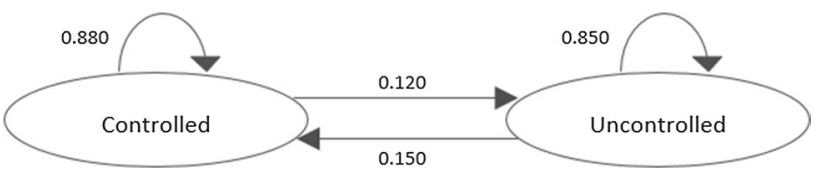

Fig. 1 Illustrative two health state Markov model structure less controlled health state conditional on experiencing a handling error [9]. Additionally, as the Demoly et al. [2] study looked at the health-care utilisation associated with only controlled or uncontrolled asthma, it was simpler to model a two health state Markov model, with any inputs that used controlled, partially controlled and uncontrolled states adjusted so that the weighted average of partially controlled and controlled was used. A one year time horizon was chosen to reflect the one year exacerbation data from the CRITIKAL study [13]. However, to reflect the time frame for budget holders' decisions in the UK, the results are also given for when three and five year time horizons were applied.

No device switching and $100 \%$ compliance were assumed over the time horizon, due to the associations with change in asthma control and possible confounding effects [14]. As this model was designed to only investigate the effect of reducing a handling error through the introduction of an error-targeted intervention, the incorporation of device switching and varying compliance rates between devices may affect the results and mask the effect of the reduction of the handling error. The one year time horizon is also in place for consistency around the no-switching assumption.

Mortality was not included in the model because the risk of mortality associated with the different devices over a one year time horizon was considered minimal. For example, official UK guidance on asthma from the National Institute for Health and Care Excellence (NICE) states that 'mortality from asthma is rare'; [15] the number of asthma-related deaths in the UK in 2012 was 1246, while the UK asthma population in the same year was more than 8 million [16]. Although NICE economic planning for asthma mentions incorporating mortality, it acknowledges that mortality data may not be available from studies due to lack of power arising from the rarity of asthma deaths and the size of the population [17]. The omission of mortality is thus a conservative simplifying assumption and by definition its inclusion would lead to even greater cost-effectiveness for the error-targeted intervention, as it has fewer exacerbations compared to DPIs.

A half cycle correction was implemented in the model to reduce bias of under-/overestimation of patients in each cycle, in line with standard practice for cost-effectiveness models [18]. Discounting of costs and QALYs was not included over

Table 1 Three-by-three transition probability matrix from Bateman et al. [19]

\begin{tabular}{llll}
\hline & Controlled & $\begin{array}{l}\text { Partially } \\
\text { Controlled }\end{array}$ & Uncontrolled \\
\hline Controlled & 0.750 & 0.190 & 0.058 \\
Partially Controlled & 0.081 & 0.730 & 0.180 \\
Uncontrolled & 0.018 & 0.130 & 0.840 \\
\hline
\end{tabular}


Table 2 Transformation to a two-by-two transition probabilities matrix from Bateman et al. [19]

\begin{tabular}{|c|c|c|}
\hline & Controlled & Uncontrolled \\
\hline Controlled & $\sum \mathbb{P}($ from $C$ or $P$ to $C$ or $P)$ & $\sum \mathbb{P}($ from $C$ or $P$ to $U$ ) \\
\hline Uncontrolled & 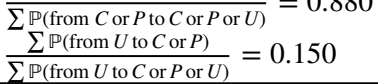 & 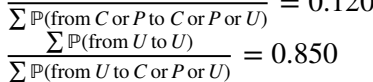 \\
\hline
\end{tabular}

$\sum$, sum; $\mathbb{P}$, probability; $\mathrm{C}$, controlled; $\mathrm{P}$, partially controlled; $\mathrm{U}$, uncontrolled

\begin{tabular}{llll}
\hline & Number of patients & Weighting & Utility values \\
\hline Controlled & 1690 & $1690 /(1690+1258)=0.57$ & 0.946 \\
Partially Controlled & 1258 & $1258 /(1690+1258)=0.43$ & 0.900 \\
$\begin{array}{l}\text { Combined Controlled and Par- } \\
\text { tially Controlled }\end{array}$ & 2948 & $\begin{array}{l}0.57 \times \text { controlled }+0.43 \times \text { partially } \\
\text { controlled }\end{array}$ & 0.926 \\
\hline
\end{tabular}

Table 3 Weighting based on CRITIKAL study and utility values from Briggs et al. [9, 12]
Table 4 Utility values and calculated disutility values for each health state from Briggs et al. [12]

\begin{tabular}{lll}
\hline & Utility values & Exacerbation disutility $^{\mathrm{a}}$ \\
\hline Controlled & 0.926 & 0.197 \\
Uncontrolled & 0.842 & 0.113 \\
Exacerbation & 0.729 & Not applicable \\
\hline
\end{tabular}

${ }^{a}$ Disutility was calculated by subtracting the exacerbation utility value from the health state utility value

GOAL study included three health states rather than two, the model took the weighted average of the controlled and partially controlled health state utility values based on the proportion of patients in each health state in the CRITIKAL study, as shown in Table 3 [9]. Utility values were applied to the two health states included in the model (controlled and uncontrolled) as shown in Table 4.

\section{Direct and indirect costs}

The model included the costs of the individual inhaler devices, and the costs associated with the degree of control [2], namely resource use and indirect costs, all of which were based on 2016/17 GBP.

Data for the average annual rate of direct resource use (physician visits, emergency room visits and hospitalisations) were identified in a systematic literature review in terms of the impact of critical handling errors on health outcomes and resource use [7]. The latest and most applicable data which provided resource use to match the two health states in our model were taken from Demoly et al. [2], which reported resource use by controlled and not-controlled status over a six month period. These data were then doubled to estimate the annual rates of resource use (shown in Table 5). These rates were then multiplied by the resource unit costs in Table 6 to provide estimates of resource use costs.

\footnotetext{
1 The predictions of the transition probabilities were made on the basis of a very large database composed of more than 129,000 weeks of follow-up.

2 This is the standard memoryless assumption of Markov models; time-dependent Markov models are known as semi-Markov models.
} 
Table 5 Parameter input values including rate of resource use and productivity loss [2]

\begin{tabular}{lcc}
\hline Parameters & Controlled (SE) & Uncontrolled (SE) \\
\hline Number of emergency room visits annually & $0.42(0.07)$ & $5.58(0.11)$ \\
Number of physician visits annually & $2.18(0.09)$ & $5.58(0.27)$ \\
Number of hospitalisations annually & $0.18(0.02)$ & $0.60(0.11)$ \\
Absenteeism-work time missed per week $(\%)$ & $6.90(2.40)$ & $7.80(2.70)$ \\
Presenteeism-impairment while at work per week $(\%)$ & $15.30(5.30)$ & $25.90(9.00)$ \\
\hline
\end{tabular}

SE standard error

Table 6 Cost input values

\begin{tabular}{|c|c|c|}
\hline Parameters & Cost GBP (SE) & References \\
\hline $\begin{array}{l}\text { Cost of error-targeted intervention, per month (priced to match } \\
\text { either Diskus }{ }^{\circledR} \text { DPI or Turbohaler }{ }^{\circledR} \text { DPI) }\end{array}$ & $\begin{array}{l}\text { Scenario 1: } £ 35.00 \text { (fixed value) } \\
\text { Scenario } 2: £ 38.00 \text { (fixed value) }\end{array}$ & $\begin{array}{l}\text { Based on the unit costs and doses of } \\
\text { Diskus }{ }^{\circledR} \text { DPI and Turbohaler }{ }^{\circledR} \text { DPI } \\
\text { below }\end{array}$ \\
\hline $\begin{array}{l}\text { Diskus }{ }^{\circledR} \text { DPI } \\
250 \mathrm{mcg} \text { fluticasone propionate } / 50 \mathrm{mcg} \text { salmeterol, per inhaler }\end{array}$ & $£ 35.00$ (fixed value) & BNF 2017 [21] \\
\hline $\begin{array}{l}\text { Turbohaler }{ }^{\circledR} \text { DPI } \\
200 \text { mcg budesonide/ } 6 \text { mcg formoterol fumarate, per inhaler }\end{array}$ & $£ 38.00$ (fixed value) & BNF 2017 [21] \\
\hline Emergency room cost per visit (currency code DZ15R) & $£ 138.00(£ 20.00)$ & NHS reference costs 2015-2016 [22] \\
\hline $\begin{array}{l}\text { General physician cost per visit (direct staff cost with qualifica- } \\
\text { tion and lasts } 9.22 \mathrm{~min} \text { ) }\end{array}$ & $£ 36.00(£ 36.00)^{\mathrm{a}}$ & PSSRU 2016 [23] \\
\hline Cost per hospitalisation (currency code DZ15R) & $\begin{array}{l}£ 1229.00(£ 1229.00)^{\mathrm{a}} \text {, or } £ 401.63 \\
\text { per day (based on average stay of } \\
3.06 \text { days) }\end{array}$ & NHS reference costs 2015-2016 [22] \\
\hline UK average salary per annum & $£ 28,200.00$ (fixed value) & ONS 2016 [24] \\
\hline
\end{tabular}

${ }^{a}$ Standard error values were not available and assumed to be equal to the mean. The average work week was assumed to be $34.8 \mathrm{~h}$, based on UK published data [25]. For the hours lost per week per asthma control state, this was calculated using data for the percentage of working hours attributed to absenteeism and presenteeism as shown in Table 5 [2], then determining the equivalent number of hours as a percentage of the UK average number of working hours

BNF British National Formulary, NHS National Health Service, ONS Office for National Statistics, PSSRU Personal Social Services Research Unit, $S E$ standard error

Device unit costs were estimated based on the assumption that patients would use a whole inhaler every 30 days with unit costs taken from the latest British National Formulary (BNF) 2017 as shown in Table 6 [21]. To compare the benefits of the removal of a single critical handling error, the cost of the error-targeted intervention was set to match either the cost of Diskus ${ }^{\circledR}$ DPI (scenario 1) or Turbohaler $^{\circledR}$ DPI (scenario 2). Then, the economically justifiable cost for the error-targeted intervention was calculated based on the $£ 20,000$ per QALY NICE threshold (scenario 3).

As noted previously, the model objective was to focus on the impact of overcoming a critical handling error; therefore, it was assumed that there were no differences in drug effectiveness that would impact on control status. This is in line with NICE guidance on ICS devices for asthma in adults, which states it is reasonable to assume that there are no differences in clinical effectiveness for ICS devices at low doses. Their assessment found that there were no consistent differences between the clinical effectiveness of the different
ICS/LABA combinations, and clinical and patient experts agreed with this finding [15].

To model indirect costs, $74.6 \%$ of patients in the model were assumed to be economically active, based on the estimated UK employment rate in April 2017 [25]. Therefore, only working patients were assumed to incur costs associated with absenteeism and presenteeism. The population working wage, which is used to calculate the indirect costs of absenteeism and presenteeism, was calculated by multiplying the estimated employment rate by the average UK salary in 2016 [24, 25].

\section{Exacerbations}

Exacerbations were only considered as an event in the model based on rates from the CRITIKAL study (calculated from the number of exacerbations per health state) [13] with their impact on utilities only occurring in the uncontrolled health state [9]. The associated costs were not modelled directly as the resource use consequences of exacerbations were 
Table 7 RR of an 'insufficient inspiratory effort' for each device [9]

\begin{tabular}{lll}
\hline Device & OR $(\mathrm{SE})$ & $\mathrm{RR}(\mathrm{SE})^{\mathrm{a}}$ \\
\hline Error-targeted intervention & $\begin{array}{l}\text { Main analysis: 1 (0) } \\
\text { Sensitivity analysis: } 1.25,1.5,1.75 \\
\text { and 2 }\end{array}$ & $\begin{array}{l}\text { Main analysis: 1 (0) } \\
\text { Sensitivity analysis: } \\
\text { transformation from }\end{array}$ \\
& & OR to RR \\
Turbohaler & & $1.19(0.197)$ \\
Diskus $^{\circledR}$ DPI & $1.30(0.11)$ & $1.28(0.197)$ \\
\hline
\end{tabular}

${ }^{a}$ All standard errors were calculated from the upper and lower 95\% confidence interval limits and assumed a Normal distribution. It was assumed that the $95 \%$ confidence interval for the error-targeted intervention was $(1,1)$

$O R$ odds ratio, $R R$ relative risk, $S E$ standard error indirectly modelled via health state resource use which implicitly included differential exacerbation rates [26]. The number of exacerbations over the one year time horizon was estimated for each device.

The expected number of exacerbations in one year were calculated by multiplying the number of patients experiencing $\mathrm{X}$ exacerbations over one year, by $\mathrm{X}$ exacerbations, for each health state [13]. For the small number of patients in the CRITIKAL study falling into the 5+ exacerbations per year category $(0.49 \%, 1.21 \%$ and $5.26 \%$ controlled, partially controlled and uncontrolled, respectively), it was assumed that they experienced 5 exacerbations per year. The expected number of exacerbations per year for the combined controlled health state was found by applying the weightings in Table 3 to the calculated expected number of exacerbations per year for controlled and partially controlled states. The resulting value for controlled, and the expected number of exacerbations in a year for a patient in the uncontrolled state were converted to probabilities of exacerbation in a week for each state, using the formula:

$P=1-\operatorname{EXP}(-r t)$,

where $r$ is the expected number of exacerbations per patient in the state in a year and $t=52$ (converting from one year to one week). This gave the weekly exacerbation rate $0.69 \%$ for the controlled state and $1.93 \%$ for the uncontrolled state, allowing the number of exacerbations to be found for each comparator across the time horizon. Due to data paucity on the cost per exacerbation for the asthma patient population in the UK, exacerbation costs themselves were not included in the total costs. Additionally, it was assumed that the resource use costs associated with each health state would contain the cost associated with an exacerbation (avoiding overestimation of cost).

\section{Risk of a critical handling error}

The CRITIKAL study, as mentioned previously, calculated the OR of a patient being in an uncontrolled asthma state for each inhaler, conditional on having made the critical handling error of 'insufficient inspiratory effort' [9]. This was the only critical handling error associated with asthma control after adjusting for patient factors including age, smoking status, and adherence. These adjusted ORs are shown in Table 7.

The CRITIKAL study assessed a variety of handling errors, using iHARP review data (a multicentre cross-sectional study of adults with asthma) for patients aged 16 years or over, receiving Step 3 and above GINA-defined asthma therapy of ICS/LABA in the UK. This resulted in 4276 patients in the iHARP database after inclusion and exclusion criteria (such as receiving antibiotics for lower respiratory tract infection in the 2 weeks prior to iHARP review-to minimise potential confounding by other medicines) were applied. Error frequency, asthma symptom control, and exacerbation rate were analysed to identify critical handling errors. The study found the association between critical handling errors and asthma control and exacerbations for a range of inhalers including DPIs and MDIs. The critical handling error of 'insufficient inspiratory effort' was made by $32 \%-38 \%$ of DPI users and was associated with uncontrolled asthma (adjusted ORs [95\% CI], 1.30 $[1.08,1.57]$ and $1.55[1.15,2.08]$ in those using Turbohaler ${ }^{\circledR}$ DPI and Diskus ${ }^{\circledR}$ DPI, respectively) and increased exacerbation rates [9].

To apply an RR of a critical handling error to the model's baseline transition probabilities, the ORs were transformed to RRs using a common statistical approach reported in Zhang et al. [27]. This approach required the ORs to be between 0.5 and 2.5, so this approach of converting an OR to an RR (based on the incidence of the outcome of interest, $P_{0}$ ) was able to be applied. Additionally, this approach required the incidence of the event to be less than $10 \%$ which was not the case in our study; therefore, this assumption was explored in the sensitivity analysis by assuming that $\mathrm{OR}$ is equal to RR. The approach reported in Zhang et al. [27] was as follows:

$\mathrm{RR}=\frac{\mathrm{OR}}{\left(1-P_{0}\right)+\left(P_{0} \times \mathrm{OR}\right)}$

The RR, adjusted for the probability of a patient experiencing a handling error, was applied to the transition probability 
Table 8 Transition probabilities for each device [19]

\begin{tabular}{ll}
\hline Transition probability & Value (calculation) \\
\hline Error-targeted intervention transition probabilities (base case transition probabilities) & \\
Controlled to controlled & 0.880 \\
Controlled to uncontrolled & 0.120 \\
Uncontrolled to controlled & 0.150 \\
Uncontrolled to uncontrolled & 0.850 \\
Diskus ${ }^{\circledR}$ DPI RR applied to the base case transition probabilities & \\
Controlled to controlled & $0.847(0.88 / 1.28)$ \\
Controlled to uncontrolled & $0.153(0.12 \times 1.28)$ \\
Uncontrolled to controlled & $0.117(0.15 / 1.28)$ \\
Uncontrolled to uncontrolled & $0.883(0.85 \times 1.28)$ \\
Turbohaler ${ }^{\circledR}$ DPI RR applied to the base case transition probabilities & \\
Controlled to controlled & $0.858(0.88 / 1.19)$ \\
Controlled to uncontrolled & $0.142(0.12 \times 1.19)$ \\
Uncontrolled to controlled & $0.126(0.15 / 1.19)$ \\
Uncontrolled to uncontrolled & $0.874(0.85 \times 1.19)$ \\
\hline
\end{tabular}

$R R$ relative risk of patients going from controlled to uncontrolled and patients remaining uncontrolled. The inverse of the RR was applied to the remainder of the transition probabilities. The transition probability matrix was then normalised to ensure that the probabilities added up to one.

As the objective of the model was to evaluate the economic and societal impact of the critical handling error of 'insufficient inspiratory effort', through the introduction into the market of an intervention designed to avoid this error, the model made the assumption that this error-targeted intervention had an RR of one (as shown in Table 7), and so the transition probabilities remained unchanged. To explore the complete or partial eradication of the 'insufficient inspiratory effort' error, the model varied the error-targeted intervention OR by an increase in 25\%,50\%, 75\% and $100 \%$ with a probability of $35.25 \%$ of experiencing a handling error, which is the average probability of each comparator. As seen from the associations found in the CRITIKAL study and Table 8 [9], the critical handling error 'insufficient inspiratory effort' increased the likelihood of a patient having uncontrolled asthma and therefore increased the likelihood of an exacerbation.

\section{Choice of outcomes}

Cost and QALY calculations were used to estimate the net monetary benefit (NMB) for the error-targeted intervention compared to either Diskus ${ }^{\circledR}$ DPI or Turbohaler ${ }^{\circledR}$ DPI in both the deterministic and probabilistic analyses, and also simultaneously in the probabilistic analyses using a costeffectiveness acceptability curve (CEAC) which effectively estimates the probability of each of the devices included, of being the most cost-effective, i.e. having the highest NMB. The formula for NMB is:

$\mathrm{NMB}=($ incremental $\mathrm{QALY} \times$ threshold $)-$ incremental cost.

Each comparator had an NMB value for three incremental cost-effectiveness ratio (ICER) thresholds: $£ 10,000$, $£ 20,000$ and $£ 30,000$ per QALY as recommended by NICE for approval [28]. The $£ 10,000$ per QALY threshold was included because drugs or devices meeting this threshold can be fast-tracked for reimbursement approval to provide faster access to innovative and cost-effective treatments [29]. The $£ 20,000$ to $£ 30,000$ per QALY threshold is the recommended threshold by NICE [28].

\section{Sensitivity analyses}

Both deterministic sensitivity analysis (DSA) and probabilistic sensitivity analysis (PSA) were conducted to evaluate the robustness of the model values.

\section{Deterministic sensitivity analysis}

A simple DSA was conducted to determine which parameters had the greatest influence on the incremental NMB (INMB) value, which compares the NMB of the main results with the sensitivity analysis NMB value, at a threshold of $£ 20,000$ per QALY by increasing/decreasing each of the input values by $20 \%$. The parameters included in the DSA were health-care unit costs, utility values, the proportion of patients starting in each health state, indirect cost inputs including UK average salary and probability of experiencing the handling error for each comparator (related to efficacy). 
Each device was analysed separately against the error-targeted intervention. A separate analysis was conducted to calculate the economically justifiable price to identify a ceiling price for an error-targeted intervention to be cost-effective at $£ 20,000$ per QALY which is the lowest cost-effectiveness threshold for NICE.

An additional sensitivity analysis was conducted to determine the effect of assuming the RRs were equal to the ORs in the model. This was included as a sensitivity analysis because there was some uncertainty around the base case transformation from OR to RR utilising the approach described above, given that Zhang et al. [27] reported that their method may not be applicable in all situations based on its technical requirements. Given that the RRs are conditional on making a critical handling error, the magnitude of this error needs to be controlled for in a Bayesian conditional probability context for the $\mathrm{OR}=\mathrm{RR}$ approach. To make the ORs probabilistic for the OR = RR approach, they were adjusted based on a Bayesian approach with the formula below:

Adjustment $=((\mathrm{OR}-1) \times \mathrm{OR})+1$.

\section{Probabilistic sensitivity analysis}

In line with standard practice for cost-utility models, PSA was performed. Where possible, the estimated standard errors (SEs) of the mean for the parameters used in the PSA were based on published data. In the absence of published data or any other data, the estimated SEs of the mean of the costs distribution were assumed to be the same as the mean cost. These values have been highlighted in the data tables above. Resource use rates followed a Gamma distribution to reflect their non-negativity, while utilities and transition probabilities followed a Beta distribution as they ranged from zero to one.

\section{Results}

\section{Base case results}

The error-targeted intervention dominates the two DPIs individually when setting its price to match each DPI separately over one year (scenario 1 at $£ 35$ and scenario 2 at $£ 38$ ), as the error-targeted intervention had a lower total cost and higher number of QALYs in each scenario. Additionally, it resulted in only 636 exacerbations per 1000 patients over a one year time horizon, compared to 677 for Turbohaler ${ }^{\circledR}$ DPI and 713 for Diskus ${ }^{\circledR}$ DPI. For a three year time horizon, there were 1864, 1987 and 2097 exacerbations per 1000 patients for the error-targeted intervention, Turbohaler ${ }^{\circledR}$ DPI and Diskus ${ }^{\circledR}$ DPI, respectively, while for five years, there were 3010, 3209 and 3388 exacerbations per 1000 patients for the error-targeted intervention, Turbohaler ${ }^{\circledR}$ DPI and Diskus ${ }^{\circledR}$ DPI, respectively.

Positive NMB for the error-targeted intervention indicated that it was cost-effective compared to both DPI devices. For one year, at a threshold of $£ 20,000$ per QALY, and incorporating both direct and indirect costs, the error-targeted intervention priced at $£ 38$ had an NMB of $£ 303.73$ over Turbohaler ${ }^{\circledR}$ DPI, and an NMB of $£ 541.94$ over Diskus ${ }^{\circledR}$ DPI (see Table 9). Similar results were found when the errortargeted intervention was priced at $£ 35$ with an NMB of $£ 340.13$ over Turbohaler ${ }^{\circledR}$ DPI, and an NMB of $£ 578.34$ over Diskus ${ }^{\circledR}$ DPI (see Table 9). The economically justifiable cost based on direct costs only for the error-targeted intervention in the one year time horizon, based on a costeffectiveness threshold of $£ 20,000$ per QALY, was calculated at $£ 50.52$ and $£ 58.83$ per error-targeted intervention (which approximates to a monthly price) compared to Turbohaler ${ }^{\circledR}$ DPI and Diskus ${ }^{\circledR}$ DPI, respectively. For the three year time horizon and the five year time horizon (see Tables 10 and 11 ), the results were approximately triple and quintuple the NMB for the one year time horizon.

\section{Deterministic sensitivity analysis}

Multiple one-way deterministic sensitivity analyses based on an increase/decrease of $20 \%$ in the value of each parameter showed that the weekly utility value for each state and the RR of moving to an uncontrolled state for the comparator were the key factors driving variance from the base case NMB result for error-targeted intervention priced at $£ 38$, as shown in Fig. 2. Similarly, the same key factors were identified when the error-targeted intervention was priced at $£ 35$ and can be found in the Appendix (Fig. 5).

The overall results of the two price scenarios did not change greatly when RR was equal to OR from the CRITIKAL study. The incremental direct costs savings compared to Diskus ${ }^{\circledR}$ DPI and Turbohaler ${ }^{\circledR}$ DPI increased by $£ 26$ and $£ 8$, respectively. The incremental QALYs decreased by 0.0031 and 0.001 for Diskus ${ }^{\circledR}$ DPI and Turbohaler ${ }^{\circledR}$ DPI, respectively.

\section{Probabilistic sensitivity analysis}

The PSA demonstrated that the two DPIs had lower number of QALYs and were more expensive compared to the error-targeted intervention priced at $£ 38$ (see Fig. 3). Additionally, the error-targeted intervention priced at $£ 38$ had a probability $>99 \%$ of being cost-effective for all ICER thresholds $£ 14,000$ or above (see Fig. 4). This was expected when the no handling errors assumption associated with the intervention was made. When the errortargeted intervention was priced at $£ 35$, it had a $100 \%$ 
Table 9 Results over one year, when the error-targeted intervention is priced at $£ 38$ and $£ 35$ compared to both DPIs

\begin{tabular}{|c|c|c|c|c|c|c|c|c|c|}
\hline Device & $\begin{array}{l}\text { Total direct } \\
\text { costs }\end{array}$ & $\begin{array}{l}\text { Total direct } \\
\text { and indirect } \\
\text { costs }\end{array}$ & $\begin{array}{l}\text { Total } \\
\text { QALYs }\end{array}$ & $\begin{array}{l}\text { Incremental } \\
\text { direct costs }\end{array}$ & $\begin{array}{l}\text { Incremental } \\
\text { direct and } \\
\text { indirect costs }\end{array}$ & $\begin{array}{l}\text { Incre- } \\
\text { mental } \\
\text { QALYs }\end{array}$ & $\begin{array}{l}\text { ICER } \\
\text { threshold }\end{array}$ & $\begin{array}{l}\text { NMB for } \\
\text { direct costs } \\
\text { only }\end{array}$ & $\begin{array}{l}\text { NMB includ- } \\
\text { ing direct and } \\
\text { indirect costs }\end{array}$ \\
\hline $\begin{array}{l}\text { Error- } \\
\text { targeted } \\
\text { interven- } \\
\text { tion at } £ 38\end{array}$ & $£ 1126$ & $£ 6833$ & 0.8885 & & & & & & \\
\hline $\begin{array}{l}\text { Turbohaler }^{\circledR} \\
\text { DPI }\end{array}$ & $£ 1171$ & $£ 7038$ & 0.8831 & $-£ 45$ & $-£ 197$ & 0.0053 & $\begin{array}{l}£ 10,000 \\
£ 20,000 \\
£ 30,000\end{array}$ & $\begin{array}{r}£ 98.40 \\
£ 151.87 \\
£ 205.34\end{array}$ & $\begin{array}{l}£ 250.26 \\
£ 303.73 \\
£ 357.20\end{array}$ \\
\hline Diskus ${ }^{\circledR}$ DPI & $£ 1175$ & $£ 7171$ & 0.8783 & $-£ 49$ & $-£ 338$ & 0.0102 & $\begin{array}{l}£ 10,000 \\
£ 20,000 \\
£ 30,000\end{array}$ & $\begin{array}{l}£ 150.97 \\
£ 252.79 \\
£ 354.60\end{array}$ & $\begin{array}{l}£ 440.13 \\
£ 541.94 \\
£ 643.75\end{array}$ \\
\hline $\begin{array}{l}\text { Error- } \\
\text { targeted } \\
\text { interven- } \\
\text { tion at } £ 35\end{array}$ & $£ 1089$ & $£ 6797$ & 0.8885 & & & & & & \\
\hline $\begin{array}{l}\text { Turbohaler }^{\circledR} \\
\text { DPI }\end{array}$ & $£ 1171$ & $£ 7030$ & 0.8831 & $-£ 81$ & $-£ 233$ & 0.0053 & $\begin{array}{l}£ 10,000 \\
£ 20,000 \\
£ 30,000\end{array}$ & $\begin{array}{l}£ 134.80 \\
£ 188.27 \\
£ 241.74\end{array}$ & $\begin{array}{l}£ 286.66 \\
£ 340.13 \\
£ 393.60\end{array}$ \\
\hline Diskus ${ }^{\circledR}$ DPI & $£ 1175$ & $£ 7171$ & 0.8783 & $-£ 86$ & $-£ 375$ & 0.0102 & $\begin{array}{l}£ 10,000 \\
£ 20,000 \\
£ 30,000\end{array}$ & $\begin{array}{l}£ 187.37 \\
£ 289.19 \\
£ 391.00\end{array}$ & $\begin{array}{l}£ 476.53 \\
£ 578.34 \\
£ 680.15\end{array}$ \\
\hline
\end{tabular}

ICER Incremental cost-effectiveness ratio, $N M B$ Net monetary benefit, $Q A L Y$ Quality-adjusted life year

Table 10 Results over three years, when the error-targeted intervention is priced at $£ 38$ and $£ 35$ compared to both DPIs

\begin{tabular}{|c|c|c|c|c|c|c|c|c|c|}
\hline Device & $\begin{array}{l}\text { Total direct } \\
\text { costs }\end{array}$ & $\begin{array}{l}\text { Total direct } \\
\text { and indirect } \\
\text { costs }\end{array}$ & $\begin{array}{l}\text { Total } \\
\text { QALYs }\end{array}$ & $\begin{array}{l}\text { Incremental } \\
\text { direct costs }\end{array}$ & $\begin{array}{l}\text { Incremental } \\
\text { direct and } \\
\text { indirect costs }\end{array}$ & $\begin{array}{l}\text { Incre- } \\
\text { mental } \\
\text { QALYs }\end{array}$ & $\begin{array}{l}\text { ICER } \\
\text { threshold }\end{array}$ & $\begin{array}{l}\text { NMB for } \\
\text { direct costs } \\
\text { only }\end{array}$ & $\begin{array}{l}\text { NMB includ- } \\
\text { ing direct and } \\
\text { indirect costs }\end{array}$ \\
\hline $\begin{array}{l}\text { Error- } \\
\text { targeted } \\
\text { interven- } \\
\text { tion at } £ 38\end{array}$ & $£ 3285$ & $£ 19,905$ & 2.5738 & & & & & & \\
\hline $\begin{array}{l}\text { Turbohaler }^{\circledR} \\
\text { DPI }\end{array}$ & $£ 3421$ & $£ 20,501$ & 2.5577 & $-£ 136$ & $-£ 596$ & 0.0162 & $\begin{array}{l}£ 10,000 \\
£ 20,000 \\
£ 30,000\end{array}$ & $\begin{array}{l}£ 298.01 \\
£ 459.95 \\
£ 621.88\end{array}$ & $\begin{array}{r}£ 757.91 \\
£ 919.84 \\
£ 1081.77\end{array}$ \\
\hline Diskus ${ }^{\circledR}$ DPI & $£ 3438$ & $£ 20,932$ & 2.5431 & $-£ 153$ & $-£ 1027$ & 0.0308 & $\begin{array}{l}£ 10,000 \\
£ 20,000 \\
£ 30,000\end{array}$ & $\begin{array}{r}£ 460.92 \\
£ 768.72 \\
£ 1076.52\end{array}$ & $\begin{array}{l}£ 1335.09 \\
£ 1642.89 \\
£ 1950.69\end{array}$ \\
\hline $\begin{array}{l}\text { Error- } \\
\text { targeted } \\
\text { interven- } \\
\text { tion at } £ 35\end{array}$ & $£ 3179$ & $£ 19,800$ & 2.5738 & & & & & & \\
\hline $\begin{array}{l}\text { Turbohaler }^{\circledR} \\
\text { DPI }\end{array}$ & $£ 3421$ & $£ 20,501$ & 2.5577 & $-£ 242$ & $-£ 702$ & 0.0162 & $\begin{array}{l}£ 10,000 \\
£ 20,000 \\
£ 30,000\end{array}$ & $\begin{array}{l}£ 403.56 \\
£ 565.50 \\
£ 727.43\end{array}$ & $\begin{array}{r}£ 863.46 \\
£ 1025.39 \\
£ 1187.32\end{array}$ \\
\hline Diskus ${ }^{\circledR}$ DPI & $£ 3438$ & $£ 20,932$ & 2.5431 & $-£ 259$ & $-£ 1133$ & 0.0308 & $\begin{array}{l}£ 10,000 \\
£ 20,000 \\
£ 30,000\end{array}$ & $\begin{array}{r}£ 566.47 \\
£ 874.27 \\
£ 1182.07\end{array}$ & $\begin{array}{l}£ 1440.64 \\
£ 1748.44 \\
£ 2056.24\end{array}$ \\
\hline
\end{tabular}

$I C E R$ Incremental cost-effectiveness ratio, $N M B$ Net monetary benefit, $Q A L Y$ Quality-adjusted life year 
Table 11 Results over five years, when the error-targeted intervention is priced at $£ 38$ and $£ 35$ compared to both DPIs

\begin{tabular}{|c|c|c|c|c|c|c|c|c|c|}
\hline Device & $\begin{array}{l}\text { Total direct } \\
\text { costs }\end{array}$ & $\begin{array}{l}\text { Total direct } \\
\text { and indirect } \\
\text { costs }\end{array}$ & $\begin{array}{l}\text { Total } \\
\text { QALYs }\end{array}$ & $\begin{array}{l}\text { Incremental } \\
\text { direct costs }\end{array}$ & $\begin{array}{l}\text { Incremental } \\
\text { direct and } \\
\text { indirect costs }\end{array}$ & $\begin{array}{l}\text { Incre- } \\
\text { mental } \\
\text { QALYs }\end{array}$ & $\begin{array}{l}\text { ICER } \\
\text { threshold }\end{array}$ & $\begin{array}{l}\text { NMB for } \\
\text { direct costs } \\
\text { only }\end{array}$ & $\begin{array}{l}\text { NMB includ- } \\
\text { ing direct and } \\
\text { indirect costs }\end{array}$ \\
\hline $\begin{array}{l}\text { Error- } \\
\text { targeted } \\
\text { interven- } \\
\text { tion at } £ 38\end{array}$ & $£ 5300$ & $£ 32,108$ & 4.1471 & & & & & & \\
\hline $\begin{array}{l}\text { Turbohaler }^{\circledR} \\
\text { DPI }\end{array}$ & $£ 5522$ & $£ 33,077$ & 4.1208 & $-£ 221$ & $-£ 969$ & 0.0263 & $\begin{array}{l}£ 10,000 \\
£ 20,000 \\
£ 30,000\end{array}$ & $\begin{array}{r}£ 484.35 \\
£ 747.53 \\
£ 1010.72\end{array}$ & $\begin{array}{l}£ 1231.80 \\
£ 1494.98 \\
£ 1758.17\end{array}$ \\
\hline Diskus ${ }^{\circledR}$ DPI & $£ 5551$ & $£ 33,779$ & 4.0971 & $-£ 250$ & $-£ 1670$ & 0.0500 & $\begin{array}{l}£ 10,000 \\
£ 20,000 \\
£ 30,000\end{array}$ & $\begin{array}{r}£ 750.25 \\
£ 1250.35 \\
£ 1750.44\end{array}$ & $\begin{array}{l}£ 2170.54 \\
£ 2670.64 \\
£ 3170.73\end{array}$ \\
\hline $\begin{array}{l}\text { Error- } \\
\text { targeted } \\
\text { interven- } \\
\text { tion at } £ 35\end{array}$ & $£ 5130$ & $£ 31,938$ & 4.1471 & & & & & & \\
\hline $\begin{array}{l}\text { Turbohaler }^{\circledR} \\
\text { DPI }\end{array}$ & $£ 5522$ & $£ 33,077$ & 4.1208 & $-£ 391$ & $-£ 1139$ & 0.0263 & $\begin{array}{l}£ 10,000 \\
£ 20,000 \\
£ 30,000\end{array}$ & $\begin{array}{r}£ 654.45 \\
£ 917.63 \\
£ 1180.82\end{array}$ & $\begin{array}{l}£ 1401.90 \\
£ 1665.08 \\
£ 1928.27\end{array}$ \\
\hline Diskus ${ }^{\circledR}$ DPI & $£ 5551$ & $£ 33,779$ & 4.0971 & $-£ 420$ & $-£ 1841$ & 0.0500 & $\begin{array}{l}£ 10,000 \\
£ 20,000 \\
£ 30,000\end{array}$ & $\begin{array}{r}£ 920.35 \\
£ 1420.45 \\
£ 1920.54\end{array}$ & $\begin{array}{l}£ 2340.64 \\
£ 2840.74 \\
£ 3340.83\end{array}$ \\
\hline
\end{tabular}

ICER Incremental cost-effectiveness ratio, $N M B$ Net monetary benefit, $Q A L Y$ Quality-adjusted life year

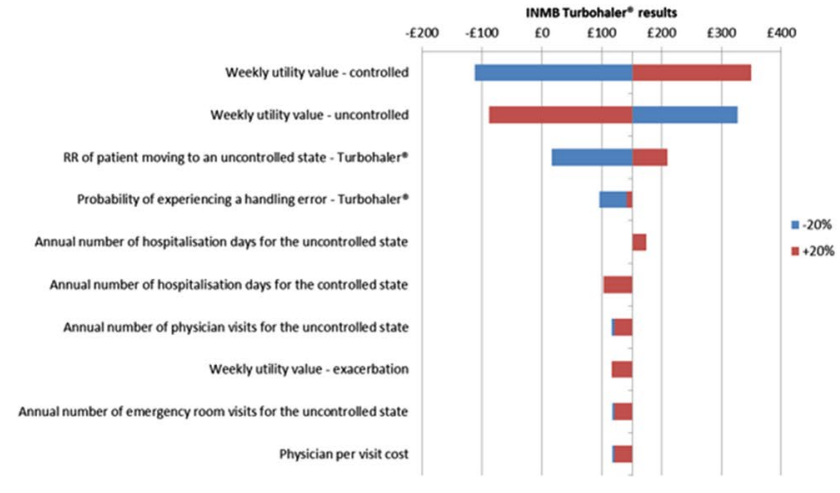

Fig. 2 Tornado diagrams showing the ten parameters that had the greatest impact on the NMB when the error-targeted intervention (priced at $£ 38$ and an ICER threshold of $£ 20,000$ per QALY) was compared to Turbohaler $^{\circledR}$ DPI or Diskus ${ }^{\circledR}$ DPI. DSA Deterministic

probability of being cost-effective for all ICER thresholds. These results can be found in the Appendix (Figs. 6 and 7).

The error-targeted intervention was cost-effective when the OR of moving to an uncontrolled health state after making an 'insufficient inspiratory effort' error increased to $1.25(\mathrm{RR}=1.15)$ compared to both comparators in both scenarios. However, when the OR was 1.50, Turbohaler ${ }^{\circledR}$ DPI became more cost-effective in both scenarios. When priced at $£ 38$, with OR 1.75 , Turbohaler ${ }^{\circledR}$ DPI became more cost-effective (see Table 12).

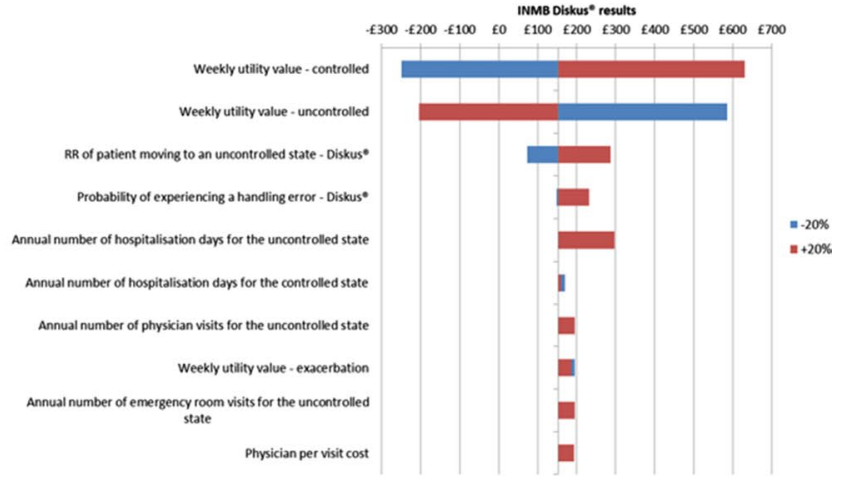

sensitivity analysis, ICER Incremental cost-effectiveness ratio, INMB Incremental net monetary benefit, $Q A L Y$ Quality-adjusted life year, $O R$ Odds ratio

\section{Discussion and conclusions}

Our study has demonstrated the economic and societal costs of eradicating the critical handling error of 'insufficient inspiratory effort' and the potential benefit of introducing an effective intervention to eliminate this error. Eradicating this critical handling error is likely to provide direct cost savings of $£ 45$ and $£ 86$ per patient and indirect cost savings of $£ 152$ and $£ 289$ per patient over one year 


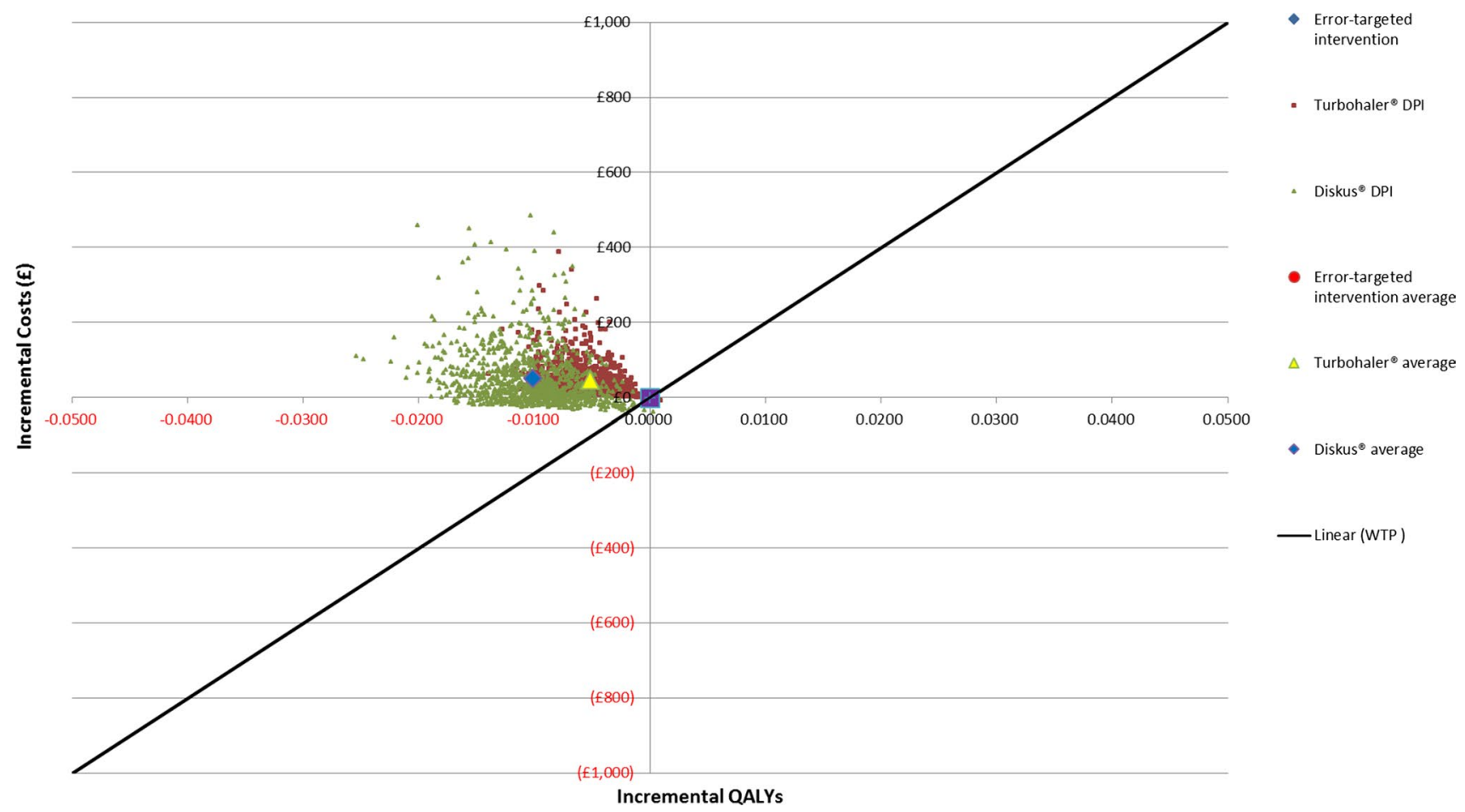

Fig. 3 PSA of the error-targeted intervention priced at $£ 38$ and an ICER threshold of $£ 20,000$ per QALY. ICER Incremental cost-effectiveness ratio, PSA Probabilistic sensitivity analysis, $Q A L Y$ Quality-adjusted life year, WTP Willingness to pay

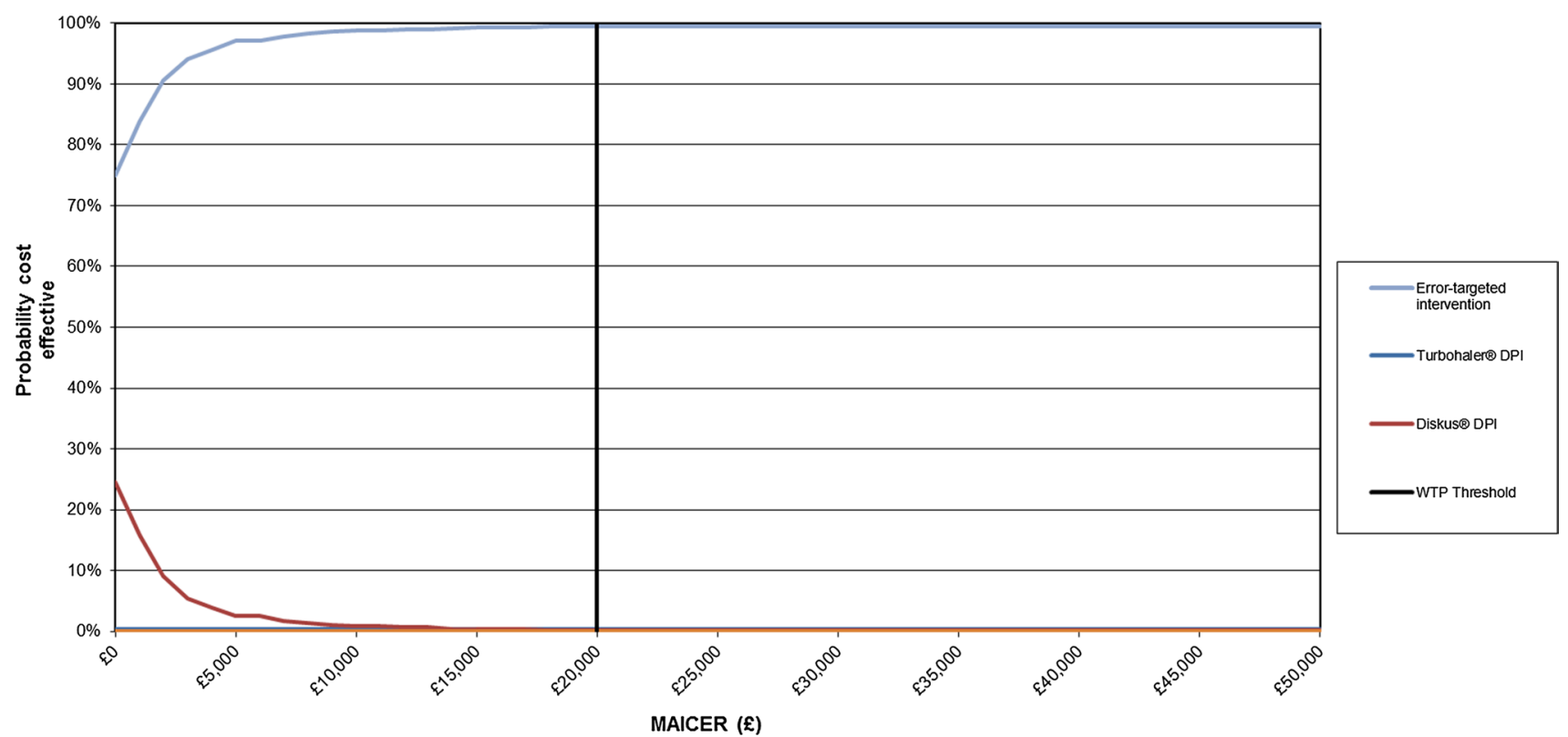

Fig. 4 CEAC based on the PSA in Fig. 2, for the error-targeted intervention priced at £38. CEAC Cost-effectiveness acceptability curve, MAICER Maximum acceptability incremental cost-effectiveness ratio, PSA Probabilistic sensitivity analysis, WTP Willingness to pay

through improved overall asthma control, compared to both Diskus ${ }^{\circledR}$ DPI and Turbohaler ${ }^{\circledR}$ DPI. This error-targeted intervention was dominant in the base case, PSA and the DSA, showing that it was less costly and offered higher QALYs than both Turbohaler ${ }^{\circledR}$ DPI and Diskus ${ }^{\circledR}$ DPI. The potential saving of avoiding the critical handling error of 
Table 12 Exploratory analysis for increasing OR values for the error-targeted intervention at an ICER threshold of £20,000 per QALY

\begin{tabular}{|c|c|c|c|c|c|c|}
\hline Scenario & OR & $\mathrm{RR}$ & $\begin{array}{l}\text { Error-targeted inter- } \\
\text { vention direct cost }\end{array}$ & $\begin{array}{l}\text { Error-targeted inter- } \\
\text { vention QALY }\end{array}$ & $\begin{array}{l}\text { NMB } \\
\text { Turbohaler } \\
\text { DPI }\end{array}$ & NMB Diskus ${ }^{\circledR}$ DPI \\
\hline \multirow{4}{*}{$\begin{array}{l}\text { Error-targeted intervention with a } \\
\text { probability of experiencing a critical } \\
\text { handling error of } 35.25 \% \text { and a price } \\
\text { of } £ 35\end{array}$} & 1.25 & 1.19 & $£ 1127$ & 0.8840 & $£ 60.25$ & $£ 161.18$ \\
\hline & 1.50 & 1.37 & $£ 1160$ & 0.8801 & $-£ 50.09$ & $£ 50.82$ \\
\hline & 1.75 & 1.53 & $£ 1171$ & 0.8831 & $£ 100.91$ & $£ 144.70$ \\
\hline & 2.00 & 1.68 & $£ 1212$ & 0.8739 & $-£ 225.76$ & $-£ 125$ \\
\hline \multirow{4}{*}{$\begin{array}{l}\text { Error-targeted intervention with a } \\
\text { probability of experiencing a critical } \\
\text { handling error of } 32.25 \% \text { and a price } \\
\text { of } £ 38\end{array}$} & 1.25 & 1.19 & $£ 1163$ & 0.8840 & $£ 23.87$ & $£ 124.78$ \\
\hline & 1.50 & 1.37 & $£ 1196$ & 0.8801 & $-£ 86.49$ & $£ 14.42$ \\
\hline & 1.75 & 1.53 & $£ 1224$ & 0.8768 & $-£ 181.10$ & $-£ 80.19$ \\
\hline & 2.00 & 1.68 & $£ 1248$ & 0.8739 & $-£ 262.16$ & $-£ 161.24$ \\
\hline
\end{tabular}

Please note a positive NMB means the error-targeted intervention is more cost-effective, a negative NMB means the comparator is cost-effective $I C E R$ Incremental cost-effectiveness ratio, $N M B$ Net monetary benefit, $O R$ Odds ratio, $Q A L Y L$ Quality-adjusted life year, $R R$ relative risk

'insufficient inspiratory effort' generates an economically justifiable price of approximately $£ 51$ and $£ 59$ per unit per month for the error-targeted intervention over one year at a willingness to pay threshold of $£ 20,000 / Q A L Y$.

Reducing or eliminating the critical handling error of 'insufficient inspiratory effort' through an error-targeted intervention, either training or improved device features, is important to reduce costs and to improve the wellbeing of patients. Recently, there has been an innovation in the development of asthma inhalers that has focused on this aspect of patient care. For example, a first in class, ICS/ LABA breath-triggered aerosol inhaler, has been designed with the objective of overcoming the requirement of DPIs for forceful inspiration and additionally does not require coordination for actuation, as for MDIs. An open-label, randomised, two-period crossover study showed that patients preferred this new inhaler over their current inhaler owing to its ease of use, with $99 \%$ of all patients successfully triggering the new inhaler at their first attempt [30]. There is therefore the possibility that new devices such as a breathtriggered aerosol device could have an important economic impact on healthcare systems, alongside their patient-related benefits. This model provides decision makers with an estimate of the economic and societal impact of eradicating a specific critical handling error and the potential advantage offered by the introduction into the market of a novel errortargeted intervention. The open-source nature of the model also allows clear and transparent presentation of the calculations and results.

To the authors' knowledge, this was the first cost-utility model to evaluate the economic and societal impact of a critical handling error associated with asthma inhaler devices.
The model assumed that, other than the 'insufficient inspiratory effort' critical handling error, all other errors were not significantly associated with asthma control for DPIs, when adjustments for patient characteristics and adherence were made. While this was reflective of the results reported in the CRITIKAL study [9], in real-world practice this may underestimate/overestimate the number and impact of other critical handling errors for patients with asthma. It was also assumed for this analysis that the intervention was associated with zero errors. In real-world practice, other errors may be found to be associated with an error-targeted intervention or the intervention might fail to eradicate the error completely. Further research on the economic evaluation of all handling error in the CRITIKAL study could potentially be carried out in the future.

There were some limitations related to the technical aspects of the model including the two health state approach and the Markovian assumption. Although modelling two health states was favoured to be consistent with the Demoly et al. [2] paper, ORs from the CRITIKAL study and provided simplicity, this approach may have reduced the granularity of the results in the model. The Markovian assumption of fixed transition probabilities over time may not be realistic and does not reflect patients potentially improving their inhaler technique over time; however, this assumption was used to simplify the model calculations and was based on the data available. Further research based on real-world data is recommended to explore time-dependent transition probabilities.

The Zhang et al. [27] approach for the transformation of ORs to RRs also recommends that the incidence of the event in the population of interest should be less than $10 \%$. 
However, the incidence of the critical handling error was higher than $10 \%$ (at 32\% and 38\% for Turbohaler ${ }^{\circledR}$ DPI and Diskus ${ }^{\circledR}$ DPI in the CRITIKAL study) and therefore the RRs calculated in the model may have been overestimated [9]. The DSA of setting the OR to equal RR (another approach which has been suggested in the literature) [31] to test the impact of this assumption, did not change the overall findings that the error-targeted intervention was cost-effective in the model. Both approaches for transforming the OR values generated similar values, which demonstrates the robustness of the results. Furthermore, no alternative transformation approach was identified for the high incidence rate.

The drug dose for each comparator in the model was selected to be similar in effectiveness. However, as previously noted, the model assumed the drug efficacy of the error-targeted intervention and each device was the same, in line with NICE findings on ICSs [15], for the model to assess the impact of the critical handling error only. By making all factors equal in each price scenario apart from the RR of the featured critical handling error, this allowed the cost and effects of the handling error to be isolated thus fulfilling the model objective. The drug doses were chosen to obtain the comparative price of the two DPIs to use in the different analyses, rather than to include efficacy based on differential drug dosing.

The transition probabilities were based on Bateman et al. [19], which included similar drugs and dosing as the model. While handling errors were not mentioned, this source may have already included handling errors. If already included, this may have had an effect on the transition probabilities resulting from the study in which case the model may overestimate the impact of handling errors through applying both transition probabilities based on this source, and RR of experiencing the handling error of 'insufficient inspiratory effort' [9]. For future research, it would be beneficial to explore the inclusion of handling errors in transition probabilities and how this would impact the results of the model.

Since the error-targeted intervention is a conceptual idea, it does not have a set price and therefore the price scenarios were based on DPI device prices-a separate analysis for each DPI to ensure that all parameters remained equal except for the impact of the critical handling error. The final results based on these prices may therefore under/overestimate the cost savings in reality with a novel intervention that eliminates the selected critical handling error. The exploratory analysis showed that the error-targeted intervention was cost-effective at OR equal to $1.25(\mathrm{RR}=1.15)$ and no longer cost-effective at OR equal to or greater than 1.50 $(\mathrm{RR} \geq 1.38)$.
The cost of the error-targeted intervention was set to that of the two comparators to enable direct comparison, as the price of an error-targeted intervention (device, training or both) is currently unknown. The model calculated the maximum economical price for the new intervention, of $£ 50.52$ and $£ 58.83$ (which approximates to a monthly price) compared to Turbohaler ${ }^{\circledR}$ DPI and Diskus ${ }^{\circledR}$ DPI, respectively. To demonstrate potential training, with these prices, the PSSRU 2016 unit cost per hour (including qualification) for a nurse (GP practice) is $£ 43$ per hour [23], so this is approximately 1.17 to $1.37 \mathrm{~h}$ of nurse time per month. Training was not included as a sole comparator in the model as it is difficult to measure its effectiveness for different devices and it may vary between patients in practice.

A limitation of the model was the exclusion of the cost per exacerbation. In the model, exacerbation costs were implicitly included in the direct costs associated with each control state. If we assumed an exacerbation utilised one emergency room visit (£138.00), one hospitalisation (£1229.00) and one general physician visit (£36.00), the additional cost would be $£ 1403.00$ per exacerbation. Due to the error-targeted intervention having a lower number of exacerbations per 1000 patients compared to Turbohaler ${ }^{\circledR}$ DPI and Diskus ${ }^{\circledR}$ DPI for all time horizons, we can state that our original assumption of no exacerbation cost was a potential underestimation of the total cost.

The current analysis does not include any other devices such as MDIs, as the aim of this study was to evaluate the economic cost of eradicating a specific critical handling error which was associated with DPIs and demonstrated a significant association with both asthma control and an increased rate of exacerbations. Including only the two DPIs included in the CRITIKAL study was deemed appropriate since NICE recommends using branded inhalers based on patient preference [32]. The model assumed that patients continued to use the same inhaler throughout the time horizon of 1 year without switching and that patients had a full year of treatment suggesting full adherence to their inhaler prescription. However, since these assumptions were applied to the error-targeted intervention and all devices in the model, no intervention or inhaler had preference over any other [23].

For future research, it would be beneficial to explore alternative ways of linking critical handling errors with exacerbations directly and also to model the health economic impact of an intervention designed to eradicate the critical handling error which affects MDIs, actuation and inhalation not corresponding, compared to MDI devices in the market [9]. MDIs were excluded from this study, because this was a study to explore the economic impact 
of eradicating one handling error which was only associated with DPIs.

A cost-utility model incorporating all critical handling errors regardless of statistical significance associated with DPIs in the CRITIKAL study would also be a potential future analysis.

In conclusion, the model in this study has shown the economic benefit of an intervention which eliminates a single critical handling error results in a higher NMB and a lower ICER. Therefore, reducing this error improves patient quality-of-life and decreases healthcare resources.

Acknowledgements The authors would like to acknowledge Vanessa Buchanan and Simon Walker from Cogentia who assisted with model critical appraisal and validation, and Antony Wright from Maverex who developed the $\mathrm{R}$ code for the cost-utility model.

TURBOHALER is a registered trademark of AstraZeneca AB.

DISKUS is a registered trademark of Glaxo Group Limited.

\section{Compliance with ethical standards}

Declaration of funding This analysis was funded by Mundipharma. Employees of Mundipharma contributed to the design of the model, analysis and interpretation of data, and the writing of this manuscript.

Conflict of interest Rebecca Forster and William C.N. Dunlop are employees of Mundipharma. Aran Ratcliffe, Megan Lewis and Amy Crossley are employees of Adelphi Values Ltd., who were funded by Mundipharma to conduct this analysis.

Open Access This article is distributed under the terms of the Creative Commons Attribution 4.0 International License (http://creativeco mmons.org/licenses/by/4.0/), which permits unrestricted use, distribution, and reproduction in any medium, provided you give appropriate credit to the original author(s) and the source, provide a link to the Creative Commons license, and indicate if changes were made.

\section{Appendix}

\section{Search strategy for targeted literature search}

An additional targeted literature search was conducted, using Embase and Medline, to identify published transitional probabilities for asthma using the GINA-defined health states of asthma to match the definitions utilised for the CRITIKAL study. The search terms included asthma, transition probability, transition probabilities, transition forces and health state. In addition, the National Institute for Health and Care Excellence and the Scottish Medicines Consortium websites were searched for any submissions for asthma containing reference to transition probabilities from January 2000 to December 2016.

\section{Probabilistic sensitivity analysis}

In line with standard practice for cost-utility models, PSA was performed using Visual Basic for Applications code in Microsoft ${ }^{\circledR}$ Excel to:

1. Estimate probabilistic results (which are likely to be more accurate than deterministic results).

2. Generate an ICER scatter plot to show the uncertainty in the results diagrammatically.

3. Generate a CEAC which shows the probability of the error-targeted intervention and with each device being cost-effective for a range of ICER thresholds (increasing incrementally by $£ 5000$ from $£ 0$ to $£ 50,000$ ).

See Figs. 5, 6 and 7.

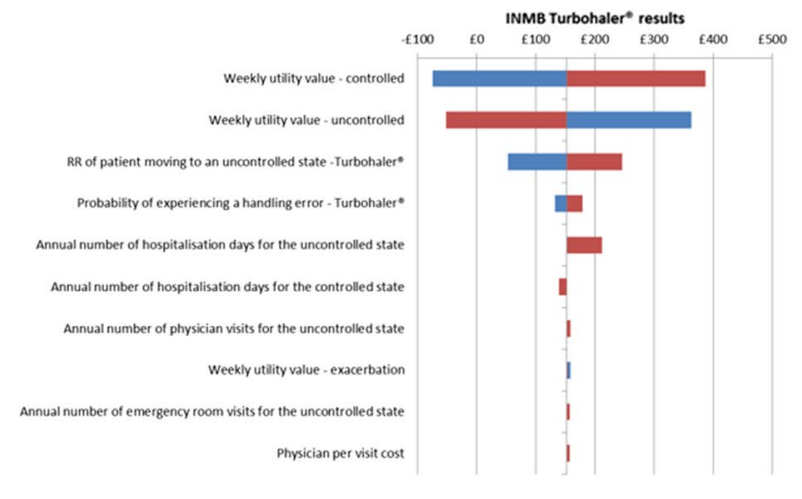

Fig. 5 Tornado diagrams showing the ten parameters that had the greatest impact on the NMB when the error-targeted intervention (priced at $£ 35$ and an ICER threshold of $£ 20,000$ per QALY) was compared to Turbohaler ${ }^{\circledR}$ DPI or Diskus ${ }^{\circledR}$ DPI. DSA Deterministic

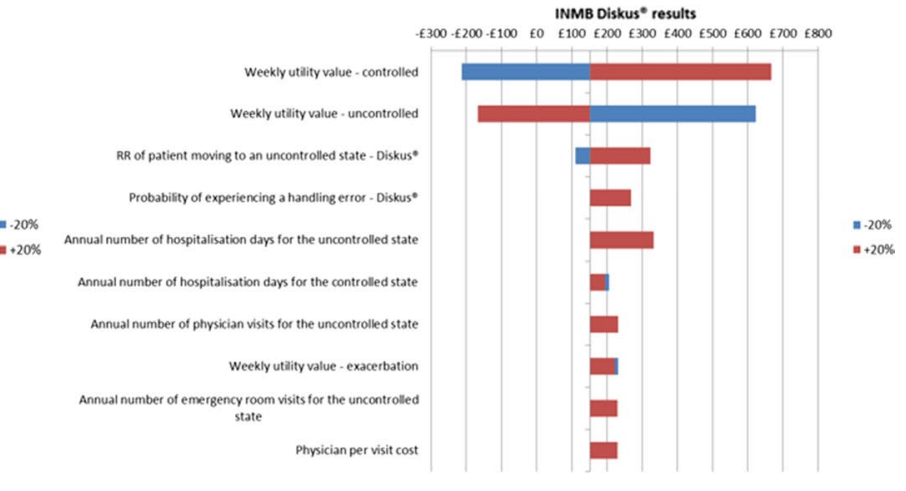

sensitivity analysis, ICER Incremental cost-effectiveness ratio, INMB Incremental net monetary benefit, $Q A L Y$ Quality-adjusted life year, $O R$ Odds ratio 


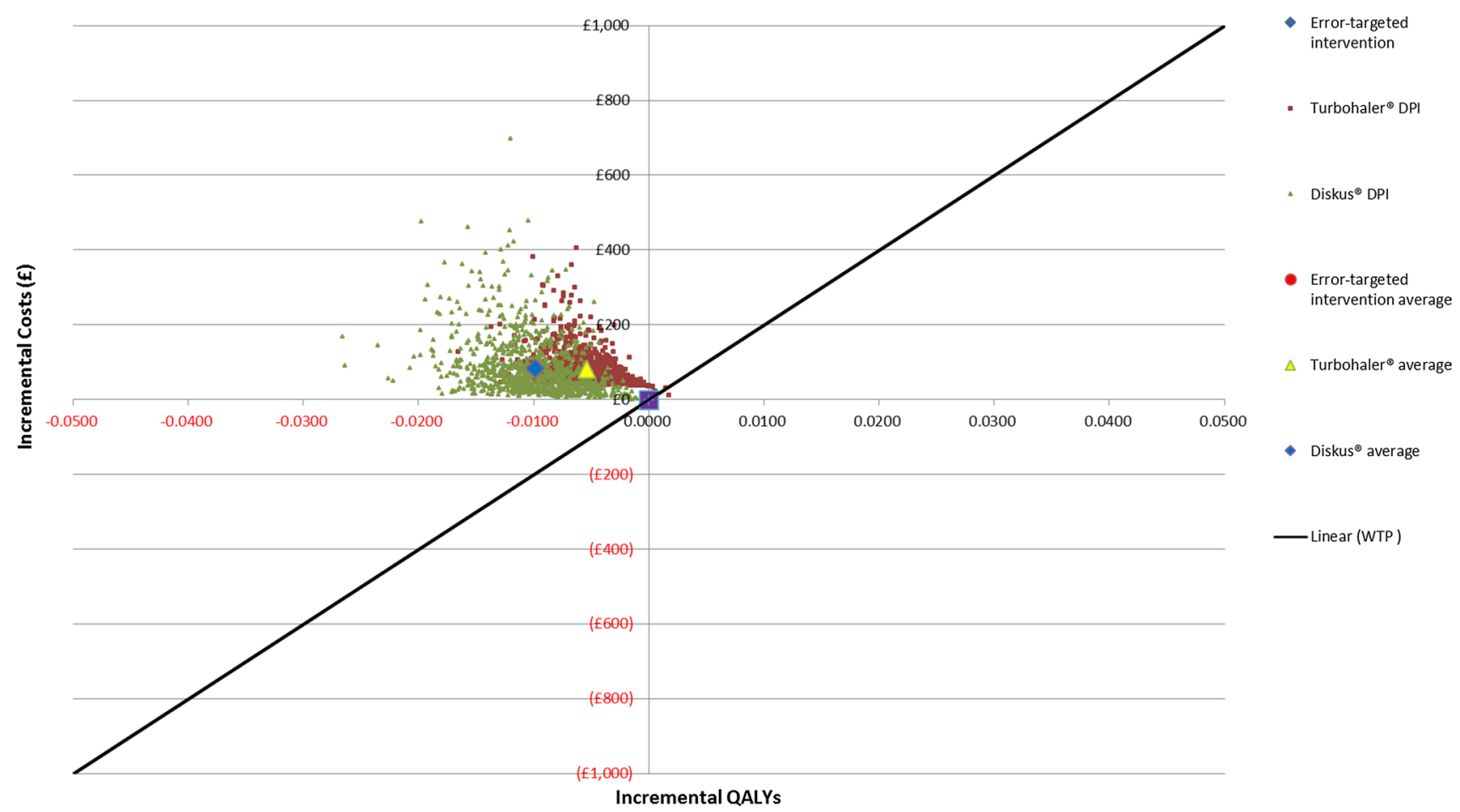

Fig. 6 PSA of the error-targeted intervention priced at $£ 35$ and an ICER threshold of $£ 20,000$ per QALY. ICER Incremental cost-effectiveness ratio, PSA Probabilistic sensitivity analysis, $Q A L Y$ Quality-adjusted life year, WTP Willingness to pay

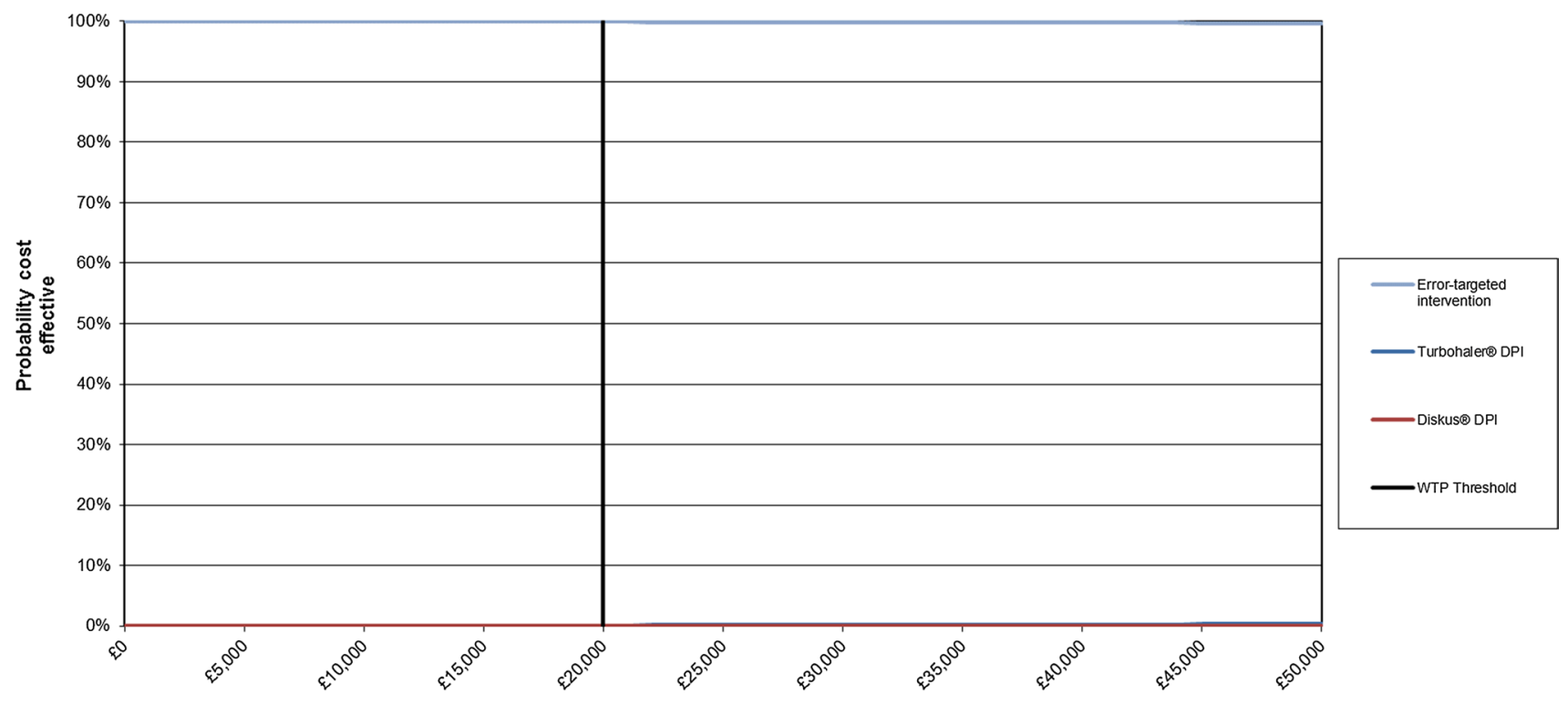

MAICER ( $($ )

Fig. 7 CEAC based on the PSA in Fig. 6, for the error-targeted intervention priced at £35. CEAC Cost-effectiveness acceptability curve, MAICER Maximum acceptability incremental cost-effectiveness ratio, PSA Probabilistic sensitivity analysis, WTP Willingness to pay 


\section{References}

1. World Health Organization. Chronic respiratory diseasesasthma. http://www.who.int/respiratory/asthma/en/. Accessed Apr 2017

2. Demoly, P., Annunziata, K., Gubba, E., Adamek, L.: Repeated cross-sectional survey of patient-reported asthma control in Europe in the past 5 years. Eur. Respir. Rev. 21(123), 66-74 (2012)

3. Doz, M., Chouaid, C., Com-Ruelle, L., Calvo, E., Brosa, M., Robert, J., et al.: The association between asthma control, health care costs, and quality of life in France and Spain. BMC Pulm. Med. 13, 15 (2013)

4. Williams, S.A., Wagner, S., Kannan, H., Bolge, S.C.: The association between asthma control and health care utilization, work productivity loss and health-related quality of life. J. Occup. Environ. Med. 51(7), 780-785 (2009)

5. Global Initiative for Asthma: Global strategy for asthma management and prevention. Global Initiative for Asthma, Calgary (2017)

6. IMS Health, IMS Medical Data, MAT Q4 2016, UK

7. Usmani, O.S., Lavorini, F., Marshall, J., et al.: Critical inhaler errors in asthma and COPD: a systematic review of impact on health outcomes. Respir. Res. 19(1), 10 (2018)

8. Roggeri, A., Micheletto, C., Roggeri, D.P.: Inhalation errors due to device switch in patients with chronic obstructive pulmonary disease and asthma: critical health and economic issues. Int. J. Chronic Obstr. Pulm. Dis. 11, 597-602 (2016)

9. Price, D.B., Roman-Rodriguez, M., McQueen, R.B., BosnicAnticevich, S., Carter, V., Gruffydd-Jones, K., et al.: Inhaler errors in the CRITIKAL study: type, frequency, and association with asthma outcomes. J. Allergy Clin. Immunol. Pract. 5(4), 1071-e9-1081-e9 (2017)

10. Crane, M.A., Jenkins, C.R., Goeman, D.P., Douglass, J.A.: Inhaler device technique can be improved in older adults through tailored education: findings from a randomised controlled trial. NPJ Prim. Care Respir. Med. 24, 14034 (2014)

11. Enstone, A., Price, G., Viejo, I., Dunlop, W.: Structured review of health economic models in asthma. Value Health 19(7), A372 (2016)

12. Briggs, A., Bousquet, J., Wallace, M., Busse, W.W., Clark, T., Pedersen, S., et al.: Cost-effectiveness of asthma control: an economic appraisal of the GOAL study. Allergy 61(5), 531-536 (2006)

13. Price, D.B., Roman-Rodriguez, M., McQueen, R.B., BosnicAnticevich, S., Carter, V., Gruffydd-jones, K.: Inhaler errors in the CRITIKAL study: type, frequency, and association with asthma outcomes (2017) (Unpublished data)

14. Thomas, M., Price, D., Chrystyn, H., Lloyd, A., Williams, A.E., von Ziegenweidt, J.: Inhaled corticosteroids for asthma: impact of practice level device switching on asthma control. BMC Pulm. Med. 9, 1 (2009)

15. National Institute for Health and Care Excellence. Technology appraisal guidance [TA138] inhaled corticosteroids for the treatment of chronic asthma in adults and in children aged 12 years and over (2008)

16. British Lung Foundation. Asthma statistics: numbers of people with asthma. https://statistics.blf.org.uk/asthma (2018). Accessed Apr 2017
17. National Institute for Health and Care Excellence. Economic plan, for 'asthma management' guideline. https://www.nice.org. uk/guidance/ng80/documents/economic-report (2016)

18. Siebert, U., Alagoz, O., Bayoumi, A.M., Jahn, B., Owens, D.K., Cohen, D.J., et al.: State-transition modeling: a report of the ISPOR-SMDM modeling good research practices task force-3. Value Health 15(6), 812-820 (2012)

19. Bateman, E.D., Reddel, H.K., Eriksson, G., Peterson, S., Ostlund, O., Sears, M.R., et al: Overall asthma control: the relationship between current control and future risk. J. Allergy Clin. Immunol. 125(3), 600-608, 8e1-8e6 (2010)

20. Bateman, E.D., Boushey, H.A., Bousquet, J., Busse, W.W., Clark, T.J.H., Pauwels, R.A., et al.: Can guideline-defined asthma control be achieved? Am. J. Respir. Crit. Care Med. 170(8), 836-844 (2004)

21. Joint Formulary Committee. British national formulary (online). BMJ Group and Pharmaceutical Press, London. http://www.medic inescomplete.com. Accessed Apr 2017

22. Department of Health. Reference costs 2015-16 (2016)

23. Curtis, L., Burns, A.: Unit costs of health and social care 2016. Personal Social Services Research Unit, University of Kent, Canterbury (2016)

24. Office for National Statistics. Annual survey of hours and earnings: 2016 provisional results. https://www.ons.gov.uk/emplo ymentandlabourmarket/peopleinwork/earningsandworkinghours/ bulletins/annualsurveyofhoursandearnings/2016provisionalresul ts\#average-earnings (2016). Accessed Apr 2017

25. Office for National Statistics. UK labour market, April 2017. https ://www.ons.gov.uk/employmentandlabourmarket/peopleinwork/ employmentandemployeetypes/bulletins/uklabourmarket/apr20 17 (2017). Accessed Apr 2017

26. iHARP database. http://iharp.org/. Accessed Apr 2017

27. Zhang, J., Kai, F.Y.: What's the relative risk?: a method of correcting the odds ratio in cohort studies of common outcomes. JAMA 280(19), 1690-1691 (1998)

28. National Institute for Health and Care Excellence. Developing NICE guidelines: the manual (2014)

29. National Institute for Health and Care Excellence. NICE and NHS England consultation on changes to the arrangements for evaluating and funding drugs and other health technologies assessed through NICE's technology appraisal and highly specialised technologies programmes: hearing before the NHS England's specialised services commissioning committee (2017)

30. Bell, D., Mansfield, L., Lomax, M.: A randomized, crossover trial evaluating patient handling, preference, and ease of use of the fluticasone propionate/formoterol breath-triggered inhaler. J. Aerosol Med Pulm Drug Deliv. 30(6), 425-434 (2016)

31. Greenland, S., Thomas, D.C.: On the need for the rare disease assumption in case-control studies. Am. J. Epidemiol. 116(3), 547-553 (1982)

32. National Institute for Health and Care Excellence. Asthma. Scenario: confirmed asthma. https://cks.nice.org.uk/asthma\#!basis forrecommendationlist (2016). Accessed Apr 2017 